\title{
Moderately trained male football players, compared to sedentary male adults, exhibit anatomical but not functional cardiac remodelling, a cross-sectional study
}

\author{
Jan E. Engvall ${ }^{1,2}$, Meriam Åström Aneq ${ }^{1}$, Eva Nylander ${ }^{1}$, Lars Brudin ${ }^{3}$ and Eva Maret ${ }^{4^{*}}$ (D)
}

\begin{abstract}
Background: Elite athletes have been the subject of great interest, but athletes at an intermediate level of physical activity have received less attention in respect to the presence of cardiac enlargement and/or hypertrophy. We hypothesized that playing football, often defined as demanding less endurance components than running or cycling, would still induce remodelling similar to sports with a dominating endurance component.

Methods: 23 male football players, age 25+/-3.9yrs. underwent exercise testing, 2D- and 3D- echocardiography and cardiac magnetic resonance (CMR). The results were compared with a control group of engineering students of similar age. The athletes exercised $12 \mathrm{~h} /$ week and the control subjects $1 \mathrm{~h} /$ week, $p<0.001$.

Results: The football players achieved a significantly higher maximal load at the exercise test (380 W vs 300W, $p<0.001$ ) as well as higher calculated maximal oxygen consumption, (49.7 vs $37.4 \mathrm{~mL} \mathrm{x} \mathrm{kg}^{-1} \times \mathrm{min}^{-1}, p<0.001$ ) compared to the sedentary group. All left ventricular (LV) volumes assessed by 3DEcho and CMR, as well as CMR left atrial (LA) volume were significantly higher in the athletes (3D-LVEDV 200 vs $154 \mathrm{~mL}$, CMR-LVEDV 229 vs $185 \mathrm{~mL}, C M R-L A$ volume 100 vs $89 \mathrm{~mL}, p<0.001, p=0.002$ and $p=0.009$ respectively). LVEF and RVEF, LV strain by CMR or by echo did not differentiate athletes from sedentary participants. Right ventricular (RV) longitudinal strain, LA and right atrial (RA) strain by CMR all showed similar results in the two groups.
\end{abstract}

Conclusion: Moderately trained intermediate level football players showed anatomical but not functional cardiac remodelling compared to sedentary males.

Keywords: Fitness, oxygen uptake, ventricular volume, deformation analysis, cardiac remodelling, echocardiography, magnetic resonance imaging

\section{Background}

Athlete's heart, defined as a physiological cardiac adaptation to exercise [1], has been extensively studied in elite athletes with the main findings of enlargement of all cardiac chambers and a proportionate increase in wall

\footnotetext{
*Correspondence: eva.maret@ki.se

${ }^{4}$ Department of Clinical Physiology, Karolinska Institutet, and Karolinska University Hospital, Stockholm, Sweden
}

Full list of author information is available at the end of the article thickness and thus in left ventricular mass (LVM) $[2,3]$. This "cardiac remodelling" is more likely to occur after a long exposure to increased hemodynamic stress, can be observed in adolescents [4] and can be observed after a few months of training in dogs [5]. It is less clear whether functional measurements such as ejection fraction and global strain remodel $[4,6]$. Individual fitness is objectively measured from a maximal cardiopulmonary exercise test (CPET) where maximal oxygen consumption otherwise in a credit line to the material. If material is not included in the article's Creative Commons licence and your intended use is not permitted by statutory regulation or exceeds the permitted use, you will need to obtain permission directly from the copyright holder. To view a copy of this licence, visit http://creativecommons.org/licenses/by/4.0/. The Creative Commons Public Domain Dedication waiver (http://creativecommons.org/publicdomain/zero/1.0/) applies to the data made available in this article, unless otherwise stated in a credit line to the data. 
$\left(\mathrm{VO}_{2 \text { max }}\right)$ is determined. Various sports are categorized in terms of the size of the endurance component of exercise [7]. Playing football is generally less demanding in terms of oxygen transport capacity than long-distance running or cycling. Still however, football has been shown to induce remodelling similar to sports with a dominating endurance component $[8,9]$. Most previous studies on cardiac adaptation in football players have not measured the actual aerobic capacity of the subjects, which is relevant since e.g. national differences between type of football and training regimes exist. Furthermore, elite athletes have been the subject of great interest, but athletes at an intermediate range of physical activity have received less attention in respect to the presence of cardiac enlargement and/or hypertrophy. We investigated a team of male football players participating in the Swedish level 2 national football league and compared with a reference population recruited among sedentary male engineering students. Our primary aim was to study whether volumetric and/or functional remodelling was present and detectable with echocardiography as well as with cardiac magnetic resonance (CMR) and if that could be related to the level of physical fitness.

\section{Methods}

\section{Subjects and design}

23 male football players, age $25 \pm 3.9$ yrs., (range 18-31) were recruited from their preparticipation health screening at the beginning of the football season and were offered a comprehensive cardiac evaluation. The control group consisted of 16 male engineering students of matching age, $23 \pm 3.2 \mathrm{yrs}$. (range 19-31), recruited from the local University. Inclusion criterion for both groups was absence of a history of cardiac or other chronic diseases, and in addition for the control group, absence of exercise on a regular basis (cut-off less than $2 \mathrm{~h}$ /week). Both groups completed a questionnaire regarding background factors and smoking habits. For additional basic demographics, see Table 1. Exclusion criteria were those that could possibly interfere with the cardiac magnetic resonance examination (CMR) such as arrhythmia, the presence of a pacemaker and claustrophobia. A flow chart depicting the inclusion process is shown in Fig. 1.

Each participant underwent two-dimensional echocardiography (2DEcho), three-dimensional echocardiography (3DEcho), exercise testing (CPET), and CMR, all within the same day. Immediately after the 2DEcho exam, volumetric analysis by 3DEcho was performed. 3D volumes were acquired without echo contrast agent. Echocardiography always preceded the exercise test while CMR, if occurring after exercise, always was preceded by at least $20 \mathrm{~min}$ of rest.

\section{Exercise test}

The athletes performed a maximum CPET in a seated position on a cycle ergometer CASE Stress Test System 6.61 (GE Healthcare, Milwaukee, WI, USA) [10]. Cycling began with $6 \mathrm{~min}$ of steady-state work at a load of $100 \mathrm{~W}$, followed by increases in load of $30 \mathrm{~W} / \mathrm{min}$ with the goal of reaching maximal exercise capacity within $8-12 \mathrm{~min}$ of cycling with increasing load. Respiratory gases were collected using an oral mask and analysed breath-by-breath

Table 1 Subject details

\begin{tabular}{|c|c|c|c|}
\hline \multirow[t]{2}{*}{ Parameter } & Athletes & Controls & \multirow[t]{2}{*}{$\begin{array}{l}\text { Difference } \\
p \text {-value }\end{array}$} \\
\hline & 23 & 16 & \\
\hline \multicolumn{4}{|l|}{ Demography } \\
\hline Age (years) & $25(18-31)$ & $23(19-31)$ & 0.329 \\
\hline Weight (kg) & $79(67-93)$ & $85(55-110)$ & 0.128 \\
\hline Height $(m)$ & $1.81(1.65-1.95)$ & $1.87(1.70-1.96)$ & 0.061 \\
\hline Body mass index (kg/m2) & $24.1(21.9-26.1)$ & $24.4(19.0-31.5)$ & 0.877 \\
\hline Body surface area (m2) & $2.00(1.78-2.25)$ & $2.12(1.63-2.43)$ & 0.043 \\
\hline Exercise per week (hours) & $12(8-20)$ & $1(0-4)$ & $<0.001$ \\
\hline Heart rate at rest (beats/min) & $58(47-85)$ & $71(59-82)$ & 0.007 \\
\hline Systolic blood pressure at rest $(\mathrm{mmHg})$ & $130(110-150)$ & $130(120-160)$ & 0.612 \\
\hline \multicolumn{4}{|l|}{ Bicycle exercise test } \\
\hline Max load (Watts) & $380(300-440)$ & $300(210-380)$ & $<0.001$ \\
\hline Max heart rate (beats/min) & $184(169-203)$ & $190(171-203)$ & 0.012 \\
\hline Calc max oxygen consumption (L/min) & $3.98(3.09-4.64)$ & $3.19(2.16-3.98)$ & $<0.001$ \\
\hline Calc max oxygen consumption ( $\mathrm{mL} / \mathrm{kg} / \mathrm{min})$ & $49.7(43.0-56.7)$ & $37.4(29.0-47.4)$ & $<0.001$ \\
\hline
\end{tabular}

Values are median and interquartile range 


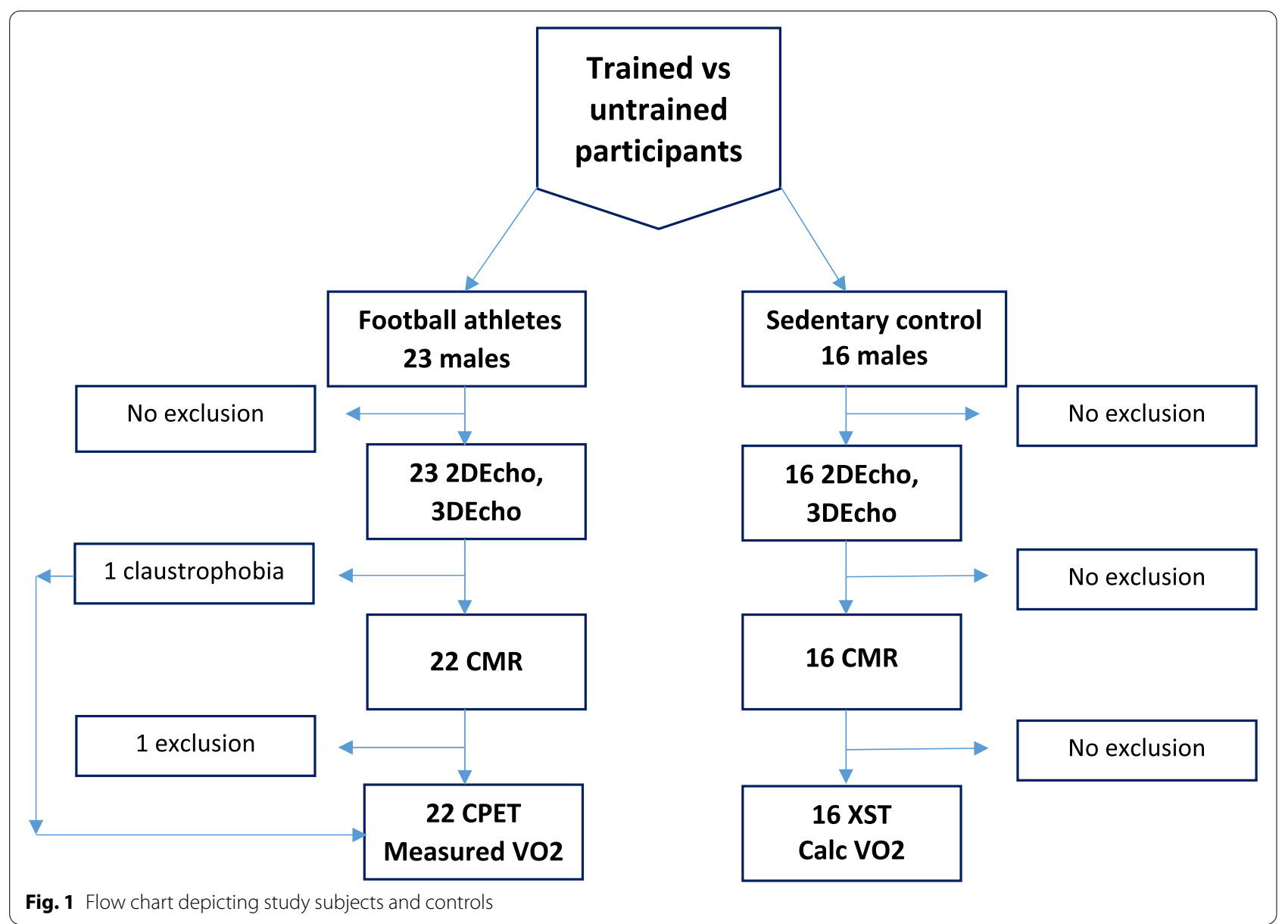

using Jaeger Oxycon Pro (Vyaire Inc., Mettawa, IL, USA). We calculated $\mathrm{VO}_{2}$ max using the values measured during the last $60 \mathrm{~s}$ of exercise and expressed the results in terms of $\mathrm{mL}^{*} \mathrm{~min}^{-1}$ and $\mathrm{mL}^{*} \mathrm{~kg}^{-1} * \mathrm{~min}^{-1}$. We considered the participants to have achieved maximal exercise capacity if the respiratory exchange ratio was $>1$ continuously for $3 \mathrm{~min}$ or longer, which was attained by all athletes. The control group performed a similar exercise protocol. Since for their part, $\mathrm{VO}_{2 \max }$ could not be measured, it was calculated from the attained exercise level and the peak heartrate [11], Table 1 and Additional file 1 . In the following, for all calculations and presentations regarding cardiac dimensions volumes and function in relation to oxygen uptake, we have used the calculated $\mathrm{VO}_{2 \max }$ in order to use the same method for athletes and controls. The only presentation of the measured $\mathrm{VO}_{2 \max }$ is in Additional file 1.

\section{Transthoracic echocardiography}

Standard transthoracic echocardiography was performed according to then current guidelines using a Vivid 7 scanner (GE Healthcare, Horten, Norway) with a $3.5 \mathrm{MHz}$
M5S ultrasound probe for 2DEcho and a 3V-D transducer for the acquisition of 3D images [12]. Two-dimensional parasternal measurements of LV septal (IVSd) and posterior wall (PWTd) thickness as well as end-diastolic LV cavity dimension (LVEDd) were measured and LVM calculated using the Devereux formula [13]. Relative wall thickness in diastole (RWTd) was calculated [12, 14]. Apical four- (4Ch) and two-chamber (2Ch) views were recorded and LV volumes (LVEDV, LVESV), stroke volume (LVSV) and ejection fraction (LVEF) were calculated using the modified biplane Simpson formula. Analysis was performed offline using EchoPac BT 12 (GE Healthcare, Horten, Norway).

LV global longitudinal strain (LVGLS) was analysed from three apical views $(4 \mathrm{Ch}, 2 \mathrm{Ch}$ and the apical longaxis view, " $3 \mathrm{Ch}$ ") using speckle tracking. LA strain was calculated on a global level, based on the relative reduction of the LA circumference in the 4Ch view [15].

Right ventricular (RV) end-diastolic dimension (RVEDd) was measured in the focused four-chamber view at the base of the RV and fractional area change (RVFAC) was calculated after delineation of the cavity 
in end-diastole and end-systole. Systolic displacement of the RV tricuspid annulus (TAPSE) was measured using M-mode positioned in the lateral annulus. Right atrial area was measured in the modified apical 4-Ch view and RA strain was calculated based on the relative reduction of the RA circumference.

A pulsed-wave Doppler with a sample volume of $5 \mathrm{~mm}$ was recorded at the tip of the mitral leaflets in the apical 4Ch-view and the early (E) and late (A) diastolic blood flow velocities were registered and measured. Tissue Doppler early diastolic velocity was recorded at the base of the LV septum and lateral wall in the apical $4 \mathrm{Ch}$-view, and a mean of the two velocities was calculated $\left(\mathrm{e}^{\prime}\right)$. The $E / e^{\prime}$-ratio was calculated as part of the evaluation of $\mathrm{LV}$ diastolic function [16]. Body surface area (BSA) was calculated and dimensions and volumes were indexed when needed.

4D-volumes of the left ventricle and the left atrium (LA) were obtained from an apical probe position. Four consecutive electrocardiographically gated beats were acquired during apnea. We analyzed the data with 4D-Auto-LVQ included in the Echopac software which also provides measurements of sphericity [17]. Additional movie files 2 and 3 show this in more detail.

\section{CMR acquisition protocol and analysis}

CMR was performed on a $1.5 \mathrm{~T}$ scanner (Siemens Avanto, Siemens Healthcare, Erlangen, Germany) equipped with a 6-element phased array body matrix coil combined with 6-elements in the spine coil. Retrospectively ECGgated images were acquired in supine position during repeated breath-holds. For cine imaging, a turbo- FLASH (fast low angle shot) sequence was used and after scout images, long-axis slices in the 4Ch-, $2 \mathrm{Ch}$ - and apical long-axis views were acquired as well as multiple parallel short-axis views, covering both ventricles from base to apex. No gadolinium contrast was given.

Analysis was performed on a workstation equipped with Segment v2.0 R5201 semiautomatic software for cardiac volumetric analysis [18]. Volumes and EF for both ventricles were measured after semi-automatic contouring of the short-axis stack of slices, excluding the papillary muscles, see Additional file 4. LVM was calculated from segmentation of the endo- and epicardial surfaces of the LV, Additional file 4. Papillary muscle volume was excluded from LVM. RV and LV atrioventricular plane displacement (AVPD) was assessed as well as peak RV lateral displacement (RVlat), based on CMR, by an automatic tracking algorithm implemented in the Segment software [19]. Global systolic LV circumferential strain (LVGCS) was calculated from feature tracking using Tomtec 2D-CPA-MR v2 (Tomtec GmbH, Germany), Additional file 5, while systolic RV longitudinal strain in the RV-4Ch view was measured using the Segment software, Additional file 6 [20,21]. We used absolute numbers to describe strain, denoting $-22 \%$ longitudinal strain as a "greater" strain value than $-20 \%$ longitudinal strain, according to current recommendations [22].

\section{Statistical analysis}

Continuous variables are presented as median and interquartile range, categorical data as frequencies. Due to the skewed distribution in some of the data points, the non-parametric Mann-Whitney U-test was used for all statistical comparisons of continuous variables between the groups. Differences between proportions were calculated with the Chi-2-test. A probability level of $<0.01$ was assumed statistically significant for descriptive data with many comparisons, but for testing the main hypothesis, $p<0.05$ was considered significant. Multiple logistic regression with backward deletion was performed for the interaction between LVEDV, RVEDV and LAESV by CMR. ICC was calculated with Medcalc ${ }^{\circledR}$ (MedCalc Software, Mariakerke, Belgium), all other statistics used Statistica v. 13 (Statsoft Inc. Tulsa, OK, USA).

\section{Reproducibility}

Interobserver variability was determined for 3D-LVEDV by echo and for LVEDV as well as for RV-strain by CMR using the intraclass correlation coefficient and according to Dahlberg [23].

\section{Results}

\section{Participant characteristics}

Descriptive data of the study population are reported in Table 1 . The control subjects were somewhat younger (2yrs), heavier $(6 \mathrm{~kg})$ and longer $(6 \mathrm{~cm})$ compared to the football players, but there were no statistical differences between the groups $(p=0.329, p=0.128$ and $p=0.061$ respectively). This also applies to body mass index (BMI 24.1 vs $24.4, p=0.88$ ) and body surface area (BSA 2.00 vs $\left.2.12 \mathrm{~m}^{2}, p=0.043\right)$. In agreement with the inclusion criteria, the control subjects exercised only $1 \mathrm{~h}$ per week vs the athletes $12 \mathrm{~h} /$ week, $p<0.001$. The controls had a higher heart rate at rest before the exercise test $(71$ * $\min ^{-1}$ vs $\left.58 * \min ^{-1}, p=0.007\right)$, and during echocardiography (see Tables 1 and 2) but no difference was found in systolic blood pressure at rest $(130 \mathrm{mmHg}$ vs $130 \mathrm{mmHg}$, $p=0.612$ ).

The football players had a higher frequency of family risk factors for cardiovascular disease such as diabetes and hypertension, but no one of the participants had any known history of hypertension, diabetes, valve disease or other cardiovascular disease. Two of the football players and four of the control subjects reported using bronchodilators to combat asthma. No one in this study was an 
Table 2 Echocardiography

\begin{tabular}{|c|c|c|c|}
\hline Parameter & Athletes & Controls & $\begin{array}{l}\text { Difference } \\
\text { p-value }\end{array}$ \\
\hline $\mathbf{N}$ & 23 & 16 & \\
\hline $\begin{array}{l}\text { Heart rate (beats * } \\
\text { min-1) }\end{array}$ & $60(41-79)$ & $72(57-100)$ & $<0.001$ \\
\hline Septum $_{d}(m m)$ & $10(7-12)$ & $9(7-11)$ & 0.044 \\
\hline $\operatorname{LVED}_{\mathrm{d}}(\mathrm{mm})$ & $56(46-68)$ & $53(47-61)$ & 0.055 \\
\hline $\mathrm{LVPWT}_{\mathrm{d}}(\mathrm{mm})$ & $9.0(7.0-11.0)$ & $8.0(6.0-10.0)$ & $<0.001$ \\
\hline $\operatorname{LVM}(\mathbf{g})$ & $225(138-268)$ & $168.5(103-231)$ & $<0.001$ \\
\hline LVED $_{\mathrm{d}}-\mathrm{A} 4 \mathrm{Ch}(\mathrm{mm})$ & $57(47-67)$ & $53(45-60)$ & 0.005 \\
\hline LA-area $\left(\mathrm{cm}^{2}\right)$ & $20.0(15.4-24.8)$ & $17.5(12.5-24.1)$ & 0.005 \\
\hline $\mathrm{RA}$-area $\left(\mathrm{cm}^{2}\right)$ & $20.0(12.1-30.9)$ & $16.0(10.5-21.9)$ & $<0.001$ \\
\hline 3D-LAvolume (mL) & $73(49-106)$ & $51(35-88)$ & $<0.001$ \\
\hline RVIT1-A4CH (mm) & $38(21-45)$ & $34(29-45)$ & 0.053 \\
\hline TAPSE (mm) & $27(17-33)$ & $26(22-28)$ & 0.009 \\
\hline RVFAC (\%) & $49(40-58)$ & $47(37-55)$ & 0.086 \\
\hline E-velocity $\left(m * s^{-1}\right)$ & $0.8(0.6-1.2)$ & $0.8(0.5-1.2)$ & 0.933 \\
\hline A-velocity $(m * s-1)$ & $0.4(0.3-0.5)$ & $0.5(0.4-1.1)$ & $<0.001$ \\
\hline EA-ratio & $2.1(1.5-3.0)$ & $1.4(0.9-2.3)$ & $<0.001$ \\
\hline e-prim-mean $\left(m^{*} \mathrm{~s}-1\right)$ & $0.17(0.11-0.24)$ & $0.17(0.10-0.19)$ & 0.746 \\
\hline E-eprim-ratio & $5.1(0.0-6.3)$ & $5.0(0.0-7.6)$ & 0.682 \\
\hline 2D-LVEDV (mL) & $176(128-239)$ & $150(112-178)$ & $<0.001$ \\
\hline 2D-LVESV (mL) & $78(53-114)$ & $63(41-77)$ & $<0.001$ \\
\hline 2D-LVEF (\%) & $56(49-64)$ & $57(53-67)$ & 0.329 \\
\hline 3D-LVEDV (mL) & $200(145-245)$ & 154 (117-195) & $<0.001$ \\
\hline 3D-LVESV (mL) & $80(60-128)$ & $67(40-93)$ & 0.003 \\
\hline 3D-LVSV (mL) & $117(79-148)$ & $91(68-107)$ & $<0.001$ \\
\hline 3D-LVEF (\%) & $59(47-67)$ & $58(50-66)$ & 1.000 \\
\hline $\begin{array}{l}\text { 2D-Echo-tissue-vol- } \\
\text { ume ratio }\end{array}$ & $1(1-1)$ & $1(0-1)$ & 0.434 \\
\hline 2D-LVGLS (\%) & $-19(-24--15)$ & $-19(-22--14)$ & 0.362 \\
\hline 3D-Sphericity & $0.45(0.33-0.73)$ & $0.33(0.24-0.48)$ & $<0.001$ \\
\hline
\end{tabular}

Values are median and interquartile range

active smoker, but three of the football players were using chewing tobacco/snuff.

All subjects were in sinus rhythm. There was no significant difference between the two groups regarding QRS duration $(109 \mathrm{~ms}$ vs $102 \mathrm{~ms}, p=0.20)$ or QRS axis $\left(77^{0} \mathrm{vs}\right.$ $\left.66^{0}, p=0.24\right)$, but six of the football players compared to two in the control group fulfilled the Sokolov-Lyon criteria for left ventricular hypertrophy.

\section{CPET}

The football players achieved a significantly higher maximal load at the exercise test $(380 \mathrm{~W}$ vs $300 \mathrm{~W}$, Table $1, p<0.001$ ) as well as higher calculated $\mathrm{VO}_{2} \max$ (49.7 vs $37.4 \mathrm{~mL} * \mathrm{~kg}^{-1} * \mathrm{~min}^{-1}, p<0.001$ ) compared to the sedentary group, but peak heart rate did not differ between groups $\left(184 *{ }^{*} \min ^{-1}\right.$ vs $\left.190 * \min ^{-1}, p=0.012\right)$. In the football players, calculated $\mathrm{VO}_{2} \max$ was lower
Table 3 Magnetic resonance (CMR)

\begin{tabular}{|c|c|c|c|}
\hline Parameter & Athletes & Controls & $\begin{array}{l}\text { Difference } \\
\text { p-value }\end{array}$ \\
\hline$N$ & 22 & 16 & \\
\hline LVEDV (mL) & $229(162-308)$ & $185(155-246)$ & 0.002 \\
\hline LVESV (mL) & $112(69-149)$ & $90(66-121)$ & 0.001 \\
\hline LVEF (\%) & $56(43-64)$ & $57(52-62)$ & 0.435 \\
\hline LVSV (mL) & $137(100-198)$ & $116(92-142)$ & 0.003 \\
\hline LVM (g) & $128(83-152)$ & $96(71-120)$ & $<0.001$ \\
\hline RVEDV (mL) & $227(177-331)$ & $196(157-264)$ & 0.006 \\
\hline RVESV (mL) & $96(60-135)$ & $79(50-122)$ & 0.036 \\
\hline RVEF (\%) & $58(53-66)$ & $58(53-68)$ & 0.891 \\
\hline $\operatorname{RVSV}(\mathrm{mL})$ & $138(114-211)$ & $113(90-143)$ & 0.001 \\
\hline LVAVPD (mm) & $15(11-19)$ & $15(9-18)$ & 0.569 \\
\hline RVAVPD (mm) & $20(13-27)$ & $20(13-24)$ & 0.492 \\
\hline RVLAT (mm) & $26(17-34)$ & $26(21-32)$ & 0.529 \\
\hline LVGCS_Tomtec (\%) & $-31(-38--23)$ & $-31(-42--27)$ & 0.680 \\
\hline RVGLS_Segment (\%) & $-20(-22--17)$ & $-18(-26--9)$ & 0.693 \\
\hline LA-4Ch-strain (\%) & $-25(-33--18)$ & $-26(-39--18)$ & 0.609 \\
\hline RA-4Ch-strain (\%) & $-22(-31--10)$ & $-24(-33--13)$ & 0.284 \\
\hline LA-volume (mL) & $100(61-134)$ & $89(49-117)$ & 0.009 \\
\hline
\end{tabular}

Values are median and interquartile range

than measured, mean difference-0.3 $0.3 \mathrm{l} / \mathrm{min}$, $p<0.001$, regression equation: calculated $\mathrm{VO}_{2 \max }{ }^{*} \mathrm{~kg}^{-1}$ " $\min ^{-1}=0.95 \mathrm{x}-1.254, \mathrm{r}=0.79, \mathrm{R}^{2}=0.63$ (Additional file 1 at https://doi.org/10.48360/zf9r-j510, [24]).

\section{LV and RV dimensions and volumes by echocardiography and CMR}

LV and RV volumes as well as LVM are reported in Tables 2 and 3.

All LV volumes (end-diastolic, end-systolic and stroke volume) assessed by 3DEcho and CMR (3D-LVEDV 200 vs $154 \mathrm{~mL}$, CMR-LVEDV 229 vs $185 \mathrm{~mL}$, 3D-LVESV 80 vs $67 \mathrm{~mL}$, CMR-LVESV 112 vs $90 \mathrm{~mL}, 3 \mathrm{D}-\mathrm{LVSV} 117$ vs $91 \mathrm{~mL}$, CMR-LVSV 137 vs $116 \mathrm{~mL} p<0.001, p=0.002$, $p=0.003, p=0.001, \mathrm{p}<0.001$ and $\mathrm{p}=0.003$ respectively) were significantly higher in the athletes. The shape of the LV expressed as the 3DEcho sphericity index, differed significantly between the two groups, being higher in the athletes, 0.45 vs. $0.33, p<0.001$, indicating a more spherical end-diastolic shape. However, CMR could not confirm this finding. LVM and relative wall thickness (RWTd by 2DEcho) were higher in the athletes (134g vs. $99 \mathrm{~g}, p<0.001,0.34$ vs. $0.30, p=0.008$ respectively) while the LVM-to-volume ratio was borderline higher, $0.50 \mathrm{~g} /$ $\mathrm{mL}$ vs. $0.47 \mathrm{~g} / \mathrm{mL}, p=0.032$. Three of the football players had an end-diastolic septal thickness on echo of $12 \mathrm{~mm}$, but no one in the sedentary group. No study person had a calculated LVM, as assessed by CMR, higher than the 
recommended upper level of normal, $184 \mathrm{~g}$ or $91 \mathrm{~g} * \mathrm{~m}^{-2}$ [25], but 11 study persons, all football players, had a calculated indexed LVM $>115 \mathrm{~g}^{*} \mathrm{~m}^{-2}$ on 2DEcho which is the upper limit of reference for LVM by linear measurements [14].

RV end-diastolic and end-systolic volumes and stroke volume were larger in the athletes, Table 3 (CMR-RVEDV 227 vs $196 \mathrm{~mL}$, CMR-RVESV 96 vs $79 \mathrm{~mL}$, CMR-RVSV 138 vs $113 \mathrm{~mL}, p=0.006, p=0.036$ and $p=0.001$ respectively). There was no difference in the left-to-right enddiastolic ventricular volume ratio between the groups (1.04 vs. $1.06, p=0.936)$. In univariate analysis adjusted for age and height, all three of LVEDV, RVEDV and LAESV by CMR correlated significantly with calculated $\mathrm{VO}_{2 \text { max }}$. In multivariate analysis, only LVEDV remained significant indicating a high interdependence between these volumes.

\section{LV and RV function by echocardiography and CMR}

Strain parameters, EF and AVPD for the LV and the RV are reported in Tables 2 and 3. AVPD for both ventricles did not differ between athletes and controls for CMR but 2DEcho TAPSE was borderline higher for athletes (CMR-LVAVPD 15 vs $15 \mathrm{~mm}$, CMR-RVLAT 26 vs $26 \mathrm{~mm}$, 2DEcho TAPSE 27 vs $26 \mathrm{~mm}, p=0.569, p=0.529$ and $p=0.009$ ). Mean values for 2DEcho, 3DEcho and CMR LVEF, CMR RVEF and 2DEcho FAC were not significantly different for the athletes compared to the controls. Furthermore, LV strain by CMR in the longitudinal or circumferential directions, longitudinal LV strain by 2DEcho or RV longitudinal strain did not differentiate athletes from sedentary participants, Table 3.

\section{Atrial size and function}

Biplane CMR LA volume was 100 vs $89 \mathrm{~mL}, p=0.009$ (Table 3) and with 3DEcho, 73 vs $51 \mathrm{ml}, p<0.001$ (Table 2). LA- and RA-strain by CMR both showed similar results in the two groups (Table 3 ).

\section{$\mathrm{LV}$ and $\mathrm{RV}$ volume and function in relation to fitness}

Calculated maximal oxygen uptake in the combined group correlated linearly with 3DEcho-LVEDV and CMR-LVEDV, $R=0.78$ and $R=0.72$, Fig. 2. Furthermore, LA-volume correlated positively with calculated $\mathrm{VO}_{2 \text { max }}, \mathrm{R}^{2}=0.39$. On the contrary, there was no correlation between calculated $\mathrm{VO}_{2}$ max and 2DEcho LVGLS $(\mathrm{R}=0.09, p=0.60)$ and with CMR-LVGCS, $\mathrm{R}=0.12$, $p=0.48$.

\section{Reproducibility}

LVEDV by 3DEcho calculated by two observers showed for all participants a mean value of $176 \mathrm{~mL}$ and a coefficient of variation (COV) $8.15 \%$ according to Dahlberg
[23]. LVEDV by CMR had a mean value of $225 \mathrm{~mL}$ and COV $6.60 \%$. CMR-RV global strain was $-19.0 \%$ and COV $3.49 \%$. The corresponding ICC values for single measurements were $\mathrm{ICC}=0.86, \mathrm{ICC}=0.86$ and $\mathrm{ICC}=0.94$.

\section{Discussion}

In this moderately trained group of football players, we found anatomical remodelling of the left and right ventricle as well as of the left and right atrium. Ventricular function parameters, such as EF, AV-plane displacement, longitudinal strain (echo) or circumferential strain (CMR) did not differ significantly between the football players and controls.

The volume load of endurance exercise is a stimulus to the excentric hypertrophy seen in sports with a high dynamic component [26, 27]. Previous categorization of sports in terms of their propensity to induce cardiac remodelling has been questioned and newer studies put more emphasis on the individual training intensity and duration, expressed as fitness that can be objectively measured in a maximal cardiopulmonary exercise test allowing the quantification of maximal oxygen consumption, $\mathrm{VO}_{2}$ max $[28]$. Earlier studies have shown a close correlation between the level of fitness and cardiac chamber sizes as well as LVM [29] which we also found in this study, further supported by findings in linear LV-dimensions.

As the training literature so far has focused mainly on elite athletes, we found it of interest to elucidate the type and extent of cardiac adaptation seen in moderately trained football players which constitute a rather large athletic population in many countries. In a meta-analysis of studies measuring $\mathrm{VO}_{2 \text { max }}$ in football players, a relationship between the competitive level of the athletes and $\mathrm{VO}_{2 \max }$ was found [30]. Elite football players had a relative maximal oxygen uptake between 57 and $63 \mathrm{~mL} / \mathrm{kg} /$ min which is similar to that reported in an older review, $60-65 \mathrm{~mL} / \mathrm{kg} / \mathrm{min}$ [31]. The football players in our study were not on a national elite level. They were training on average $12 \mathrm{~h} /$ week and their average $\mathrm{VO}_{2 \max }$ was $49 \mathrm{~mL} /$ $\mathrm{kg} / \mathrm{min}$. In a large Scandinavian study, Norwegian male football players from the elite and first division league, underwent echocardiography, focusing on dimensions [9]. It revealed larger dimensions of all four cardiac chambers, indexed for BSA, compared to control subjcts. LV mass was also elevated, whereas LVEF did not differ between athletes and controls. Other functional parameters were not described in that study. Muir et al. (1999) also reported higher LV dimensions and mass in elite football players compared to controls [32]. Systolic functional parameters were not described, E/A was significantly higher in the athletes, however, a lower heart 

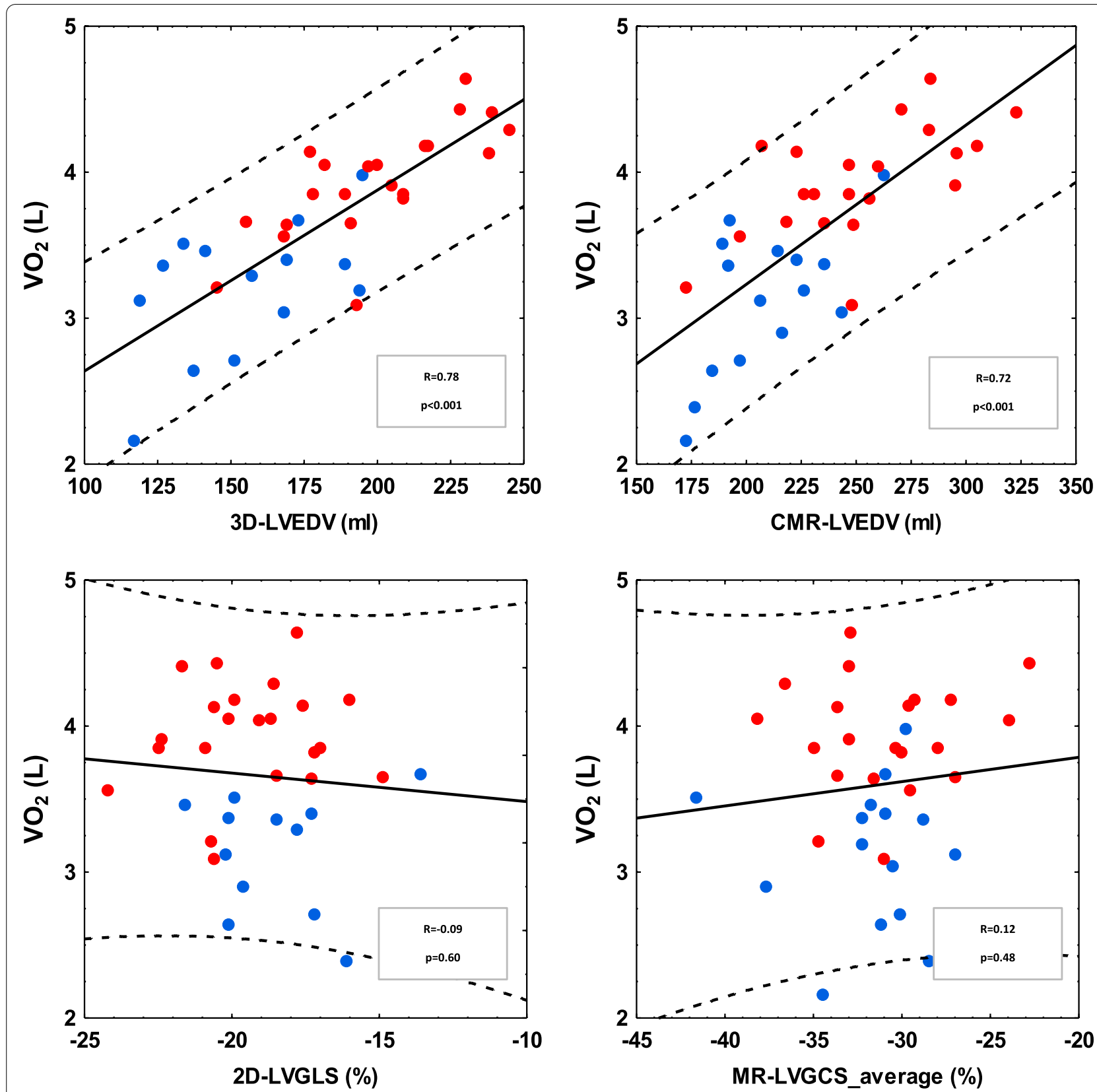

Fig. 2 Correlation between aerobic capacity expressed as calculated $\mathrm{VO}_{2 \max }$ and left ventricular end-diastolic volume (LVEDV) and left ventricular function expressed as left ventricular strain (LVGLS= left ventricular global longitudinal strain, LVGCS = left ventricular global circumferential strain). Red symbols $=$ football players, blue $=$ controls. Volumes shown in upper panels, strain in lower. Echo variables to the left and CMR to the right

rate most probably contributed to this. Later, Akova et al. (2005) described echocardiographic structural and functional measurements in 12 basketball and 20 football players, compared to sedentary controls [33]. Average $\mathrm{VO}_{2 \text { max }}$ in football players was $56 \mathrm{~mL} / \mathrm{kg} / \mathrm{min}, \mathrm{LV}$ dimensions and mass were elevated compared to controls, E-velocity or E/A ratio did not differ, neither did the myocardial performance index.
In the present study we used both echocardiography and CMR to characterize remodelling, with principally similar differences between athletes and controls, although the dimensions and volumes were not numerically equal. Echocardiography has in previous studies consistently shown lower ventricular volumes than CMR and cardiac CT, which has been regarded to be due to a tendency to favour inclusion of trabeculae in 
the thickness of the LV wall [34, 35]. Since chamber volumes are somewhat larger in CMR than in 3DEcho and 2DEcho and calculated LVM somewhat smaller when compared with 2DEcho, mainly due to the effects of calculation algorithms used in 2DEcho, method specific reference values are necessary to apply. 3DEcho and the use of contrast in $2 \mathrm{D}$ and 3DEcho have provided chamber quantification results closer to that provided by CMR [34, 36] .

Systolic functional measurements, i.e. ejection fraction, GLS (2DEcho) and GCS (CMR) did not differ between the athletes and their controls in the present study. Measurement of tissue velocity using pulsed Tissue Doppler as well as deformation analysis (strain) based on speckle tracking have been shown to be more sensitive for subtle changes in LV and RV systolic function than ejection fraction, also in athletes $[6,37]$. However, we could not corroborate significant differences in LV-, RV- and LA-strain between groups and we could not find a significant correlation between aerobic capacity and strain measurements. From a meta- analysis of LV strain in athletes, Beaumont et al. concluded that data are heterogeneous regarding GLS [38]. There are however studies in high- performing endurance athletes showing lower (less negative) GLS compared to less trained or untrained subjects [39]. In the present study, absolute strain values differed between methods such as MR feature tracking GCS and 2DEcho GLS, but this is expected since GCS and GLS measure different directions of deformation and methods for feature tracking and speckle tracking echocardiography differ [20]. In a recent CMR study, Starekova et al. reported higher LV volumes and mass in football players than controls, and also lower LV and RV longitudinal strain as well as LV radial strain [40]. The aerobic capacity was not measured in that study but the football players were reported to be professional athletes.

To summarize, football players on a moderate competitional level, training on average $12 \mathrm{~h} /$ week (various training modalities) had an average $\mathrm{VO}_{2} \max 49 \mathrm{~mL} / \mathrm{kg} /$ min which was significantly higher than in an untrained control group. The football players had significantly larger heart chamber dimensions and higher LV mass than controls. Systolic ventricular function parameters did not differ significantly between athletes and controls. Whether the type of athletic activity or the training dose is the main explanation to this remains to be proven. It has been suggested that an improved diastolic LV function is related to changes in systolic function parameters in endurance athletes. This is, however, also difficult to evaluate since many diastolic function measures are heart rate dependent which is seldom sufficiently taken into account.
Our data provide information about the degree of cardiac enlargement that may occur in moderately trained football players, which may be valuable when evaluating athletes with suspected heart disease or screened by echocardiography or CMR. It is important to measure the aerobic capacity of the athletes for an optimal definition of normality.

\section{Limitations}

$\mathrm{VO}_{2}$ max was measured in the athletes to characterize their aerobic capacity, but for comparisons between athletes and control subjects, the calculated $\mathrm{VO}_{2} \max$ was used in both groups.

\section{Conclusion}

Even moderate physical training such as practiced in an intermediate level football team, induces cardiac anatomical but not functional remodelling. Oxygen uptake should be taken into consideration when assessing cardiac size even in moderately trained individuals. This study adds valuable insight into training effects in athletes at an intermediate training level, as defined from oxygen uptake measurements.

\begin{abstract}
Abbreviations
AVPD: Atrio-ventricular plane displacement; BMI: Body mass index; BSA: Body surface area; CMR: Cardiac magnetic resonance imaging; COV: Coefficient of variation; CPET: Cardiopulmonary exercise testing; FLASH: Fast low-angle short sequence; ICC: Intra-class correlation coefficient; IVSd: Interventricular septal diameter in diastole; LA: Left atrium; LAESV: Left atrial end-systolic volume; LV: Left ventricle; LVM: Left ventricular mass; LVEDd: Left ventricular end-diastolic diameter; LVEDV: Left ventricular end-diastolic volume; LVESV: Left ventricular end-systolic volume; LVEF: Left ventricular ejection fraction; LVGCS: Left ventricular global circumferential strain; LVGLS: Left ventricular global longitudinal strain; PWTd: Posterior wall thickness in diastole; RA: Right atrium; RV: Right ventricle; RVEDd: Right ventricular end-diastolic diameter in diastole; RVEDV: Right ventricle end-diastolic volume; RVESV: Right ventricle end-systolic volume; RVFAC: Fractional area change of the right ventricle; RVGLS: Right ventricular global longitudinal strain; RVIT: Right ventricle inflow tract; RVSV: Right ventricle stroke volume; RVEF: Right ventricular ejection fraction; RWTd: Relative wall thickness in diastole; SV: Stroke volume; TAPSE: Tricuspid annulus peak systolic excursion; $\mathrm{VO}_{2}$ max: Maximal oxygen uptake.
\end{abstract}

\section{Supplementary Information}

The online version contains supplementary material available at https://doi. org/10.1186/s12947-021-00263-0.

Additional file 1. Computation of regression equation between measured VO2max and calculated VO2max, developed in the group of athletes.

Additional file 2. Segmentation and calculation of volumes and ejection fraction based on 3D echocardiography volume in an athlete. Note the large LVEDV and the higher sphericity value compared to the control in Additional file 3 .

Additional file 3. Segmentation and calculation of volumes and ejection fraction based on 3D echocardiography volume in a control participant. Note lower LVEDV than for the athlete in Additional file 2.

Additional file 4. Supervised automatic segmentation of left ventricular MR slices for volumes, ejection fraction and left ventricular mass, using 
Segment. Cineloop shows tracking of the endo- and epicardium over the cardiac cycle.

Additional file 5. Automatic segmentation and calculation of circumferential LV strain using feature tracking in the 2D-Cardiac Performance Analysis software. Cine-loop shows tracking of the endo- and epicardium over the cardiac cycle.

Additional file 6. Tracking and calculation of RV global longitudinal and wall strain using feature tracking in Segment. Note the much higher GLS value in the RV free wall compared to the septum.

\section{Acknowledgements}

The technicians performing echocardiography, bicycle stress testing and CMR at Ryhov county hospital, Jönköping, Sweden, are gratefully acknowledged for investigating the participants.

\section{Authors' contributions}

JEE acquired and analysed the data, drafted, reviewed and finalized the manuscript, MÅA critically reviewed the manuscript, EN drafted and critically reviewed the manuscript, LB performed statistical analyses and critically reviewed the manuscript, EM planned the study, acquired and analysed the data, drafted, reviewed and finalized the manuscript. All authors have had full access and take full responsibility for the data. All authors read and approved the final manuscript.

\section{Funding}

Grant support from Futurum-the Academy for Healthcare, Jönköping County Council, grants no 81951, 157681 and ALF Grants Region Ostergotland, grant 900,161 is gratefully acknowledged. Open access funding provided by Karolinska Institute.

\section{Availability of data and materials}

The data that support the study findings are available from the corresponding author upon reasonable request. The underlying data for the calculated VO2 vs measured VO2 (Additional file 1) can be publicly accessed as a document published at Linkoping University Electronic press, https://doi.org/10.48360/ zf9r-j510.

\section{Declarations}

\section{Ethics approval and consent to participate}

The regional Ethical Review Board in Linköping Sweden approved the study protocol (Registration numbers M80-08, 2010/302-32 and 2011/430-32). The study was performed in accordance with the Declaration of Helsinki. All participants gave written informed consent before inclusion in the study.

\section{Consent for publication}

Not applicable.

\section{Competing interests}

The authors declare that they have no conflicts of interest, financial or otherwise.

\section{Author details}

'Department of Clinical Physiology and Department of Health, Medicine and Caring Sciences, Linkoping University, Linkoping, Sweden. ${ }^{2} \mathrm{CMIV}$ Center for Medical Image Science and Visualization, Linkoping University, Linkoping, Sweden. ${ }^{3}$ Department of Clinical Physiology, Kalmar County Hospital and Department of Health, Medicine and Caring Sciences, Linkoping University, Linkoping, Sweden. ${ }^{4}$ Department of Clinical Physiology, Karolinska Institutet, and Karolinska University Hospital, Stockholm, Sweden.

Received: 21 March 2021 Accepted: 22 September 2021

Published online: 11 November 2021

\section{References}

1. Beaudry R, Haykowsky MJ, Baggish A, La Gerche A. A Modern Definition of the Athlete's Heart-for Research and the Clinic. Cardiol Clin. 2016;34(4):507-14.

2. Kovacs R, Baggish AL. Cardiovascular adaptation in athletes. Trends Cardiovasc Med. 2016;26(1):46-52.

3. Utomi V, Oxborough D, Whyte GP, Somauroo J, Sharma S, Shave R, et al. Systematic review and meta-analysis of training mode, imaging modality and body size influences on the morphology and function of the male athlete's heart. Heart. 2013;99(23):1727-33.

4. Rundqvist L, Engvall J, Faresjo M, Carlsson E, Blomstrand P. Regular endurance training in adolescents impacts atrial and ventricular size and function. Eur Heart J Cardiovasc Imaging. 2017;18(6):681-7.

5. Stepien RL, Hinchcliff KW, Constable PD, Olson J. Effect of endurance training on cardiac morphology in Alaskan sled dogs. J Appl Physiol (1985). 1998;85(4):1368-75.

6. Stohr EJ, McDonnell B, Thompson J, Stone K, Bull T, Houston R, et al. Left ventricular mechanics in humans with high aerobic fitness: adaptation independent of structural remodelling, arterial haemodynamics and heart rate. J Physiol. 2012;590(9):2107-19.

7. Pelliccia A, Culasso F, Di Paolo FM, Maron BJ. Physiologic left ventricular cavity dilatation in elite athletes. Ann Intern Med. 1999;130(1):23-31.

8. Chamari K, Hachana Y, Kaouech F, Jeddi R, Moussa-Chamari I, Wisloff U. Endurance training and testing with the ball in young elite soccer players. Br J Sports Med. 2005;39(1):24-8.

9. Gjerdalen GF, Hisdal J, Solberg EE, Andersen TE, Radunovic Z, Steine K. The Scandinavian athlete's heart; echocardiographic characteristics of male professional football players. Scand J Med Sci Sports. 2014;24(5):e372-80.

10. Borg GA. Psychophysical bases of perceived exertion. Med Sci Sports Exerc. 1982;14(5):377-81.

11. Astrand PO, Ryhming I. A nomogram for calculation of aerobic capacity (physical fitness) from pulse rate during sub-maximal work. J Appl Physiol. 1954;7(2):218-21.

12. Lang RM, Bierig M, Devereux RB, Flachskampf FA, Foster E, Pellikka PA, et al. Recommendations for chamber quantification. Eur J Echocardiogr. 2006;7(2):79-108

13. Devereux RB, Casale PN, Kligfield P, Eisenberg RR, Miller D, Campo E, et al. Performance of primary and derived M-mode echocardiographic measurements for detection of left ventricular hypertrophy in necropsied subjects and in patients with systemic hypertension, mitral regurgitation and dilated cardiomyopathy. Am J Cardiol. 1986;57(15):1388-93.

14. Lang RM, Badano LP, Mor-Avi V, Afilalo J, Armstrong A, Ernande L, et al. Recommendations for cardiac chamber quantification by echocardiography in adults: an update from the American Society of Echocardiography and the European Association of Cardiovascular Imaging. Eur Heart J Cardiovasc Imaging. 2015;16(3):233-70.

15. Kobayashi Y, Moneghetti KJ, Boralkar K, Amsallem M, Tuzovic M, Liang D, et al. Challenging the complementarity of different metrics of left atrial function: insight from a cardiomyopathy-based study. Eur Heart J Cardiovasc Imaging. 2017;18(10):1153-62.

16. Nagueh SF, Smiseth OA, Appleton CP, Byrd BF 3rd, Dokainish H, Edvardsen $T$, et al. Recommendations for the Evaluation of Left Ventricular Diastolic Function by Echocardiography: An Update from the American Society of Echocardiography and the European Association of Cardiovascular Imaging. Eur Heart J Cardiovasc Imaging. 2016;17(12):1321-60.

17. Mannaerts HF, van der Heide JA, Kamp O, Stoel MG, Twisk J, Visser CA. Early identification of left ventricular remodelling after myocardial infarction, assessed by transthoracic 3D echocardiography. Eur Heart J. 2004;25(8):680-7.

18. Heiberg E, Sjogren J, Ugander M, Carlsson M, Engblom H, Arheden $\mathrm{H}$. Design and validation of Segment--freely available software for cardiovascular image analysis. BMC Med Imaging. 2010;10:1.

19. Seemann F, Pahlm U, Steding-Ehrenborg K, Ostenfeld E, Erlinge D, Dubois-Rande $J \mathrm{~L}$, et al. Time-resolved tracking of the atrioventricular plane displacement in Cardiovascular Magnetic Resonance (CMR) images. BMC Med Imaging. 2017;17(1):19.

20. Barreiro-Pérez M, Curione D, Symons R, Claus P, Voigt JU, Bogaert J. Left ventricular global myocardial strain assessment comparing the reproducibility of four commercially available CMR-feature tracking algorithms. Eur Radiol. 2018;28(12):5137-47. https://doi.org/10.1007/s00330-018-5538-4. 
21. Morais P, Marchi A, Bogaert JA, Dresselaers T, Heyde B, D'Hooge J, et al. Cardiovascular magnetic resonance myocardial feature tracking using a non-rigid, elastic image registration algorithm: assessment of variability in a real-life clinical setting. J Cardiovasc Magn Reson. 2017;19(1):24.

22. Badano LP, Kolias TJ, Muraru D, Abraham TP, Aurigemma G, Edvardsen $T$, et al. Standardization of left atrial, right ventricular, and right atrial deformation imaging using two-dimensional speckle tracking echocardiography: a consensus document of the EACVI/ASE/Industry Task Force to standardize deformation imaging. Eur Heart J Cardiovasc Imaging. 2018;19(6):591-600.

23. Dahlberg G. Statistical methods for medical and biological students. London: George Allen \& Unwin Ltd.; 1940.

24. Recalibration of calculated $\mathrm{VO} 2$ max against measured VO2max [Internet] Linkoping University Electronic Press. 2021. Available from: urn:nbn:se:liu: diva-173319.

25. Kawel-Boehm N, Maceira A, Valsangiacomo-Buechel ER, Vogel-Claussen J, Turkbey EB, Williams R, et al. Normal values for cardiovascular magnetic resonance in adults and children. J Cardiovasc Magn Reson. 2015;17:29.

26. Maron BJ, Pelliccia A. The heart of trained athletes: cardiac remodeling and the risks of sports, including sudden death. Circulation. 2006;114(15):1633-44.

27. Weeks KL, McMullen JR. The athlete's heart vs. the failing heart: can signaling explain the two distinct outcomes? Physiology (Bethesda) 2011;26(2):97-105.

28. Bernardino G, de la Garza MS, Domenech-Ximenos B, Prat-Gonzalez S, Perea RJ, Blanco I, et al. Three-dimensional regional bi-ventricular shape remodeling is associated with exercise capacity in endurance athletes. Eur J Appl Physiol. 2020;120(6):1227-35.

29. Steding K, Engblom H, Buhre T, Carlsson M, Mosen H, Wohlfart B, et al. Relation between cardiac dimensions and peak oxygen uptake. J Cardiovasc Magn Reson. 2010;12:8.

30. Slimani M, Znazen H, Miarka B, Bragazzi NL. Maximum Oxygen Uptake of Male Soccer Players According to their Competitive Level, Playing Position and Age Group: Implication from a Network Meta-Analysis. J Hum Kinet. 2019;66:233-45

31. Ekblom B. Applied physiology of soccer. Sports Med. 1986;3(1):50-60.

32. Muir DF, MacGregor GD, McCann GP, Hillis WS. The prevalence of left ventricular hypertrophy in elite professional footballers. Int J Cardiol. 1999;71(2):129-34.

33. Akova B, Yesilbursa D, Sekir U, Gur H, Serdar A. Myocardial performance and aortic elastic properties in elite basketball and soccer players: relationship with aerobic and anaerobic capacity. J Sports Sci Med. 2005;4(2):185-94.

34. Jenner J, Sorensson P, Pernow J, Caidahl K, Eriksson MJ. Contrast Enhancement and Image Quality Influence Two- and Three-dimensional Echocardiographic Determination of Left Ventricular Volumes: Comparison With Magnetic Resonance Imaging. Clin Med Insights Cardiol. 2019;13:1179546819831980.

35. Polte CL, Lagerstrand KM, Gao SA, Lamm CR, Bech-Hanssen O. Quantification of Left Ventricular Linear, Areal and Volumetric Dimensions: A Phantom and in Vivo Comparison of 2-D and Real-Time 3-D Echocardiography with Cardiovascular Magnetic Resonance. Ultrasound Med Biol. 2015:41(7):1981-90.

36. Hoffmann R, Barletta G, von Bardeleben S, Vanoverschelde JL, Kasprzak J, Greis C, et al. Analysis of left ventricular volumes and function: a multicenter comparison of cardiac magnetic resonance imaging, cine ventriculography, and unenhanced and contrast-enhanced two-dimensional and three-dimensional echocardiography. J Am Soc Echocardiogr. 2014;27(3):292-301.

37. Weiner RB, DeLuca JR, Wang F, Lin J, Wasfy MM, Berkstresser B, et al. Exercise-Induced Left Ventricular Remodeling Among Competitive Athletes: A Phasic Phenomenon. Circ Cardiovasc Imaging. 2015;8(12).

38. Beaumont A, Grace F, Richards J, Hough J, Oxborough D, Sculthorpe N. Left Ventricular Speckle Tracking-Derived Cardiac Strain and Cardiac Twist Mechanics in Athletes: A Systematic Review and Meta-Analysis of Controlled Studies. Sports Med. 2017;47(6):1145-70.

39. Dores H, Mendes L, Dinis P, Cardim N, Monge JC, Santos JF. Myocardial deformation and volume of exercise: a new overlap between pathology and athlete's heart? Int J Cardiovasc Imaging. 2018;34(12):1869-75.

40. Starekova J, Thottakara T, Lund GK, Welsch GH, Brunner FJ, Muellerleile K, et al. Increased myocardial mass and attenuation of myocardial strain in professional male soccer players and competitive male triathletes. Int J Cardiovasc Imaging. 2020;36(11):2187-97.

\section{Publisher's Note}

Springer Nature remains neutral with regard to jurisdictional claims in published maps and institutional affiliations.
Ready to submit your research? Choose BMC and benefit from:

- fast, convenient online submission

- thorough peer review by experienced researchers in your field

- rapid publication on acceptance

- support for research data, including large and complex data types

- gold Open Access which fosters wider collaboration and increased citations

- maximum visibility for your research: over 100M website views per year

At BMC, research is always in progress.

Learn more biomedcentral.com/submissions 